\title{
A SINGLE STAGE DC-DC CONVERTER FEASIBLE TO BATTERY CHARGING FROM PV PANELS WITH HIGH VOLTAGE STEP UP CAPABILITY
}

\author{
Paulo P. Praça; Gustavo A. L. Henn; Ranoyca N. A. L. S.; Demercil S. Oliveira; Luiz H. S. C. Barreto \\ Energy and Control Processing Group - GPEC / Department of Electrical Engineering / Universidade Federal do Ceará \\ Centro de Tecnologia - Campus do Pici, Bl.705 \\ Fortaleza-CE, Brazil, 60455-760 / Phone: +55 853366.9586 \\ E-mail:paulopp@dee.ufc.br,gustavo.henn@dee.ufc.br,ranoyca@dee.ufc.br,demercil@dee.ufc.br, lbarreto@dee.ufc.br
}

\begin{abstract}
This paper presents a dc-de power converter integrated in such a way to obtain, in a single conversion stage, the maximum energy extraction from photovoltaic panels, battery charging and discharging dynamic control, and high voltage step-up to feed the inverter DC bus, also operating with soft-switching capability. Although this idea can be applied to most of the high voltage gain topologies, this paper is based on a structure derived from the half-bridge boost converter. Thus, a $500 \mathrm{~W}$ prototype, with input voltage of $24 \mathrm{~V}$ and output voltage of $200 \mathrm{~V}$, has been developed with the purpose of obtaining the experimental results and validate the proposed converter. High efficiency is achieved, above $92.5 \%$, confirming the expected operation and functionalities necessary for the proposed application.
\end{abstract}

\section{Key words}

Soft-Switching, single conversion stage, battery charger, high voltage step-up, photovoltaic energy.

\section{Introduction}

The growing use of alternative energy sources, such as photovoltaic panels, wind energy conversion systems, and fuel cells, brings news challenges for the power electronic society and industry. In particular, small and distributed generation systems, isolated or grid-connected types, are the future trends for this technology. It is predictable that in the future most of small consumers can act as an energy seller to the utility. Then the optimization of the efficiency, volume, weight, and cost of power converters are key features to the viability of these technologies.

In the last few years, photovoltaic panels were used only in isolated systems, in order to charge battery banks or in pumping systems, and the traditional power converters were able to achieve maximum power point operation and battery charge control. Nowadays, many systems use an ac power supply and a low voltage inverter associated with a low frequency transformer to provide a sinusoidal voltage waveform with the appropriated voltage level. However, this solution presents high weight and appreciable losses due to the high currents processed by the inverter and due to the low frequency transformer. Thus, an additional stage is necessary to step the low level voltage up from the battery bank $(12 \mathrm{~V}, 24 \mathrm{~V}$, or $48 \mathrm{~V})$ to the higher voltage level of the inverter de link $(200 \mathrm{~V}$ or $400 \mathrm{~V})$. As traditional step-up converters are not feasible to provide such high voltage gain, typical solutions use one high frequency isolated stage to achieve the high step-up voltage gain. Recently, nonisolated dc-dc converters with high voltage gain capability were successfully introduced [1], [2]. However, in systems where photovoltaic panels and battery banks are required, two dc-dc stages are still necessary, as shown in Fig. 1a.

Within this context, this paper proposes the integration of the battery charger stage, the photovoltaic power stage and the high voltage step-up stage in a single-stage power converter. From this new concept, many high step-up voltage power converters can be obtained resulting in new topologies with all aforementioned characteristics.

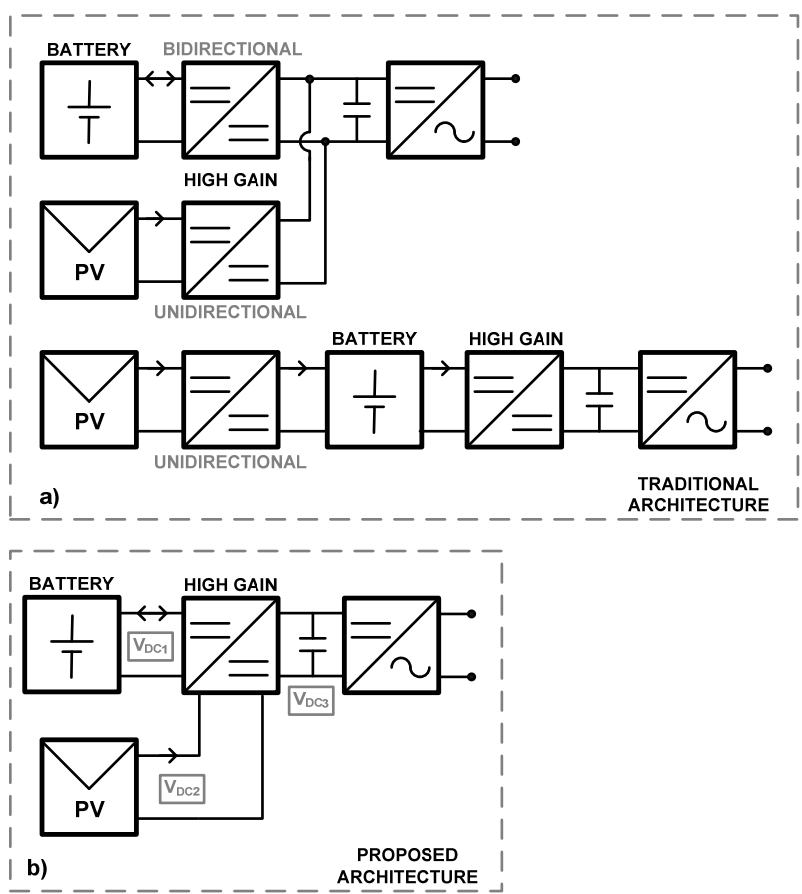

Fig. 1. a ) Conventional Architecture b) Proposed Architecture

\section{Conception of Topologies}

Some high voltage gain topologies have three dc links as shown in Fig. $1 \mathrm{~b}$, where $V_{D C 3}$ feeds the inverter with a higher voltage than that of the remaining ones. According to the proposal, the battery bank and the photovoltaic panel can be connected to the low voltage $V_{D C l}$ or $V_{D C 2}$, depending on the available voltage levels. Considering typical applications under $2 \mathrm{~kW}$, battery banks voltage levels can be $12 \mathrm{~V}, 24 \mathrm{~V}$ or $48 \mathrm{~V}$ (in order to avoid the connection of many units in series) and photovoltaic panels can be arranged to establish a dc link 
with voltage level equal to about twice that of the former link. The bidirectional characteristic of the half-bridge topology allows either charging the battery from the PV array or feeding $V_{D C 3}$. Besides, the use of resonant capacitors in the half-bridge capacitors allows soft switching (ZVS or ZCS) of the switches. The integrated topology resulting from the boost half bridge is then shown in Fig. 2. The main advantage of this topology is the low voltage stress across the active switches, low input current ripple and simplicity, what results in higher efficiency. Applying the concept to new topologies, such as those based on the three-state switching cell [3], [4] (Fig. 3, with higher efficiency characteristic), and to voltage multipliers cells [5], [6] (Fig. 4, with reduced magnetic volume), it also results in integrated topologies with similar characteristics, as many other topologies can be created.

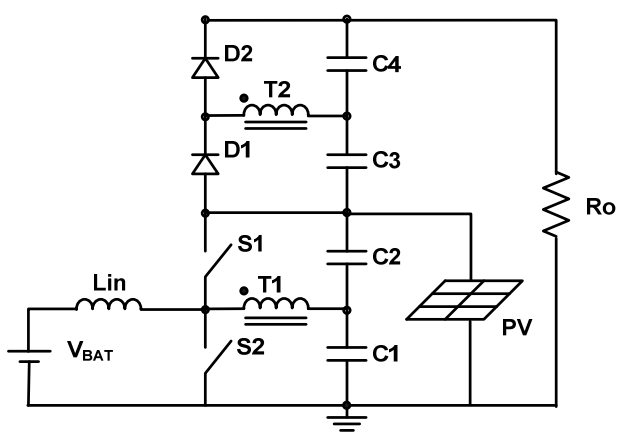

Fig. 2. Structure 1 using a PV system and a battery.

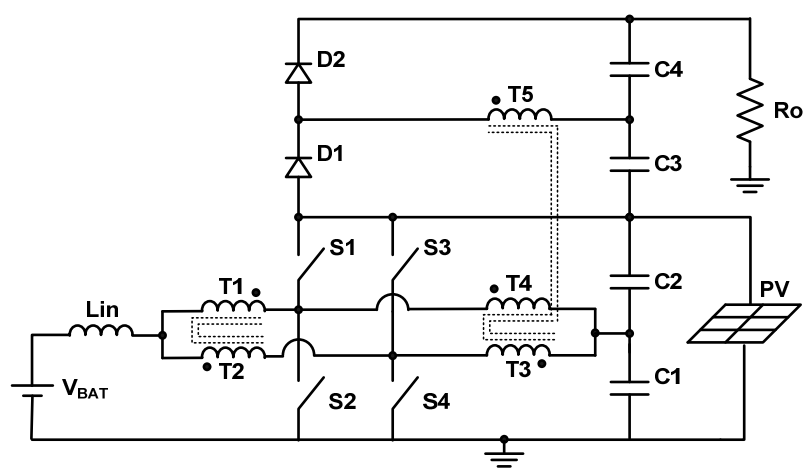

Fig. 3. Structure 2 using a PV system and a battery.

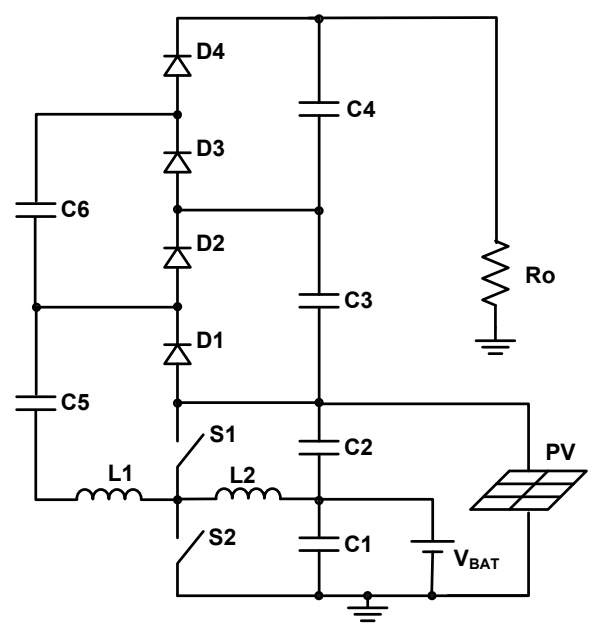

Fig. 4. Structure 3 using a PV system and a battery.
In this paper all analyzis and experimental results are based on the topology presented in Fig. 2.

\section{Static Gain}

The output voltage at any given moment can be expressed as the sum of the voltages across each output capacitor, $\mathrm{C} 1, \mathrm{C} 2, \mathrm{C} 3 \mathrm{e} \mathrm{C} 4$, as presented in equation (1).

$$
V o=V_{C 1}+V_{C 2}+V_{C 3}+V_{C 4}
$$

Relation (2) can be obtained observing that the voltage across the inductors $\mathrm{L}_{\mathrm{r} 1}$ and $\mathrm{L}_{\mathrm{r} 2}$ must be null during a switching cycle period, the voltage across the capacitor $\mathrm{V}_{\mathrm{C} 2}$ can be expressed by (2).

$$
V_{C 2}=\frac{D \cdot V i n}{1-D}
$$

Due to the transformer relation (n), it must be noticed that the voltage across $\mathrm{C} 1$ are related to the voltage across $\mathrm{C} 3$ according 4 and.

$$
\begin{gathered}
V_{C 1}=\text { Vin } \\
V_{C 3}=\text { n.Vin }
\end{gathered}
$$

Similarly to the condition presented on equation (3), the voltage across $\mathrm{C} 4$ has an direct relation to the voltage across $\mathrm{C} 2$ and the transformer relation (n), as shown in (6).

$$
V_{C 4}=n \cdot \frac{D \cdot V i n}{1-D}
$$

Substituting (3)-(6) in (1), it can be determined the static gain, as shown in equation (7).

$$
G=\frac{V_{o}}{\operatorname{Vin}}=\frac{1+n}{1-D}
$$

Figure 5 presents the curves relating the static gain (G) with the duty cycle (D) for different values of (n).

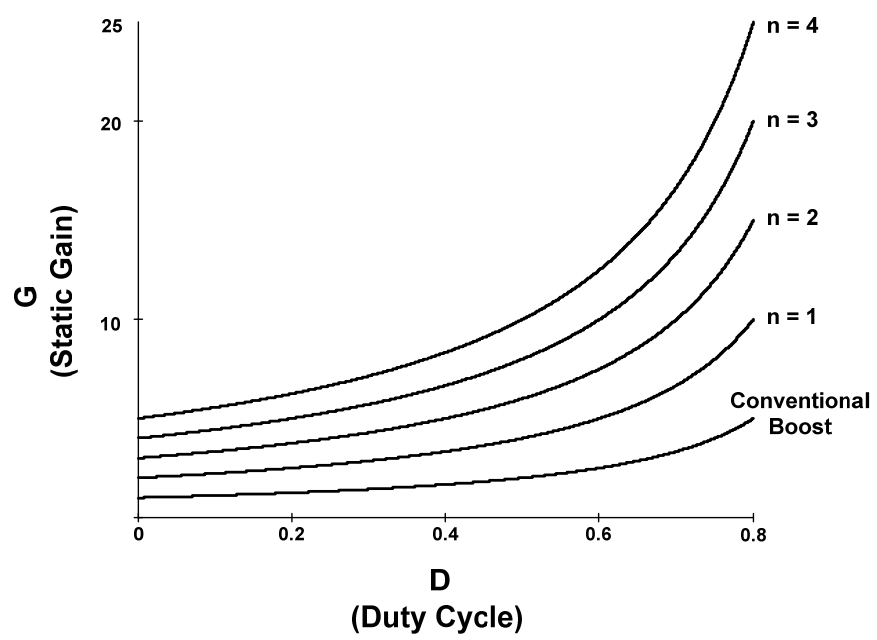

Fig .5. Relation G X D For Different Values Of N.

\section{Operation Principle}

This section presents the operation principle from the high voltage gain boost converter. For the theoretical 
analysis, it will be considered that the input voltage (Vin) and output current (Io) are ripple free and all devices are ideal.

From Figure 6, it can be observed the main theoretical waveforms, which illustrate the details of the operation principle stages explained above.

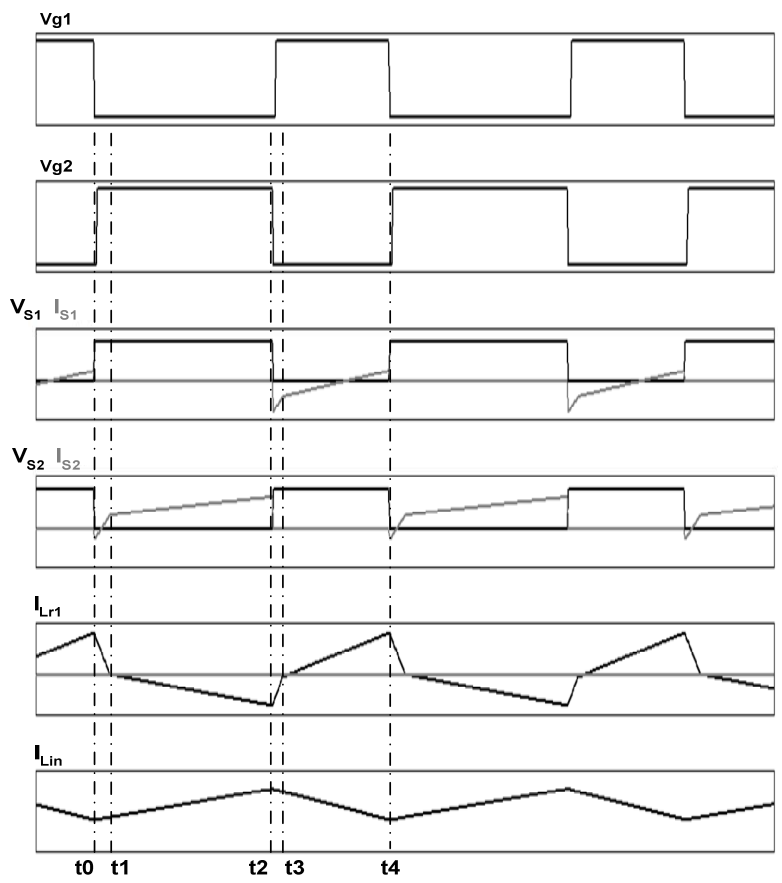

Fig .6. Main theoretical waveforms.

First Stage $\left[\mathbf{t}_{\mathbf{0}}-\mathbf{t}_{\mathbf{1}}\right]-$ At $t_{0}, S_{1}$ is turned-off and $S_{2}$ is maintained turned-on, as presented in Figure 6. On this stage, the difference between the conduced current due to the transformer leakage and the input current flows through the anti-parallel diode of S2 and decreases linearly. This stage ends when the current on the primary side of the transformer is zero.

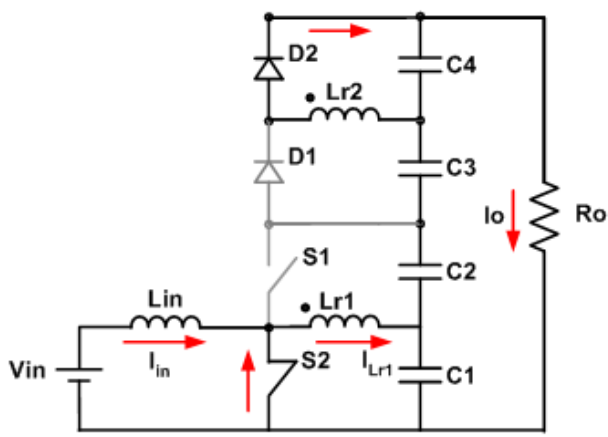

Fig .7. First Stage.

Second Stage $\left[\mathbf{t}_{\mathbf{1}}-\mathbf{t}_{\mathbf{2}}\right]$ - On this stage, the current through the primary side is added to the input current and conduced through the switch S2. The secondary circuit charges the capacitor C3 through diode D1.

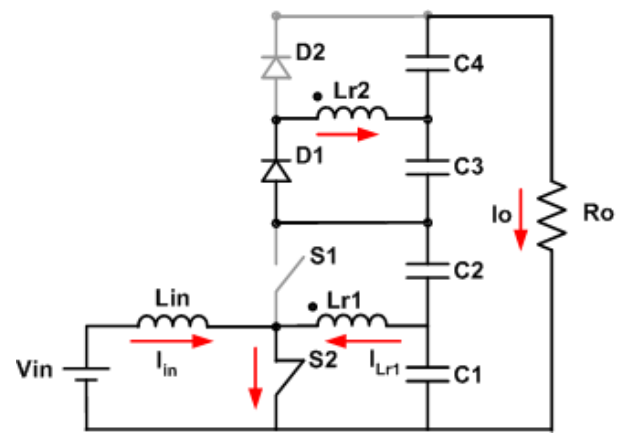

Fig .8. Second Stage.

Third Stage $\left[\mathbf{t}_{\mathbf{2}}-\mathbf{t}_{\mathbf{3}}\right]$ - This stage begins when S2 turns-off and S1 turns-on. The current that flows through $\mathrm{S} 1$ is the sum of the input current and the one through the transformer primary side, and increases linearly. This stage ends when the current on the primary reaches zero.

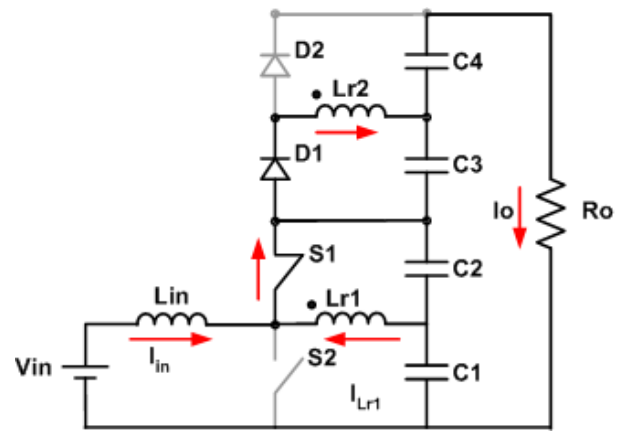

Fig .9. Third Stage.

Fourth Stage $\left[\mathbf{t}_{\mathbf{3}}-\mathbf{t}_{\mathbf{4}}\right]$ - On this stage, the current on the transformer primary side is the sum of the input current and the one that flows through $\mathrm{C} 2$. The secondary circuit charges $\mathrm{C} 4$ through diode D2. This stage ends when S2 turns-on and S1 turns-off.

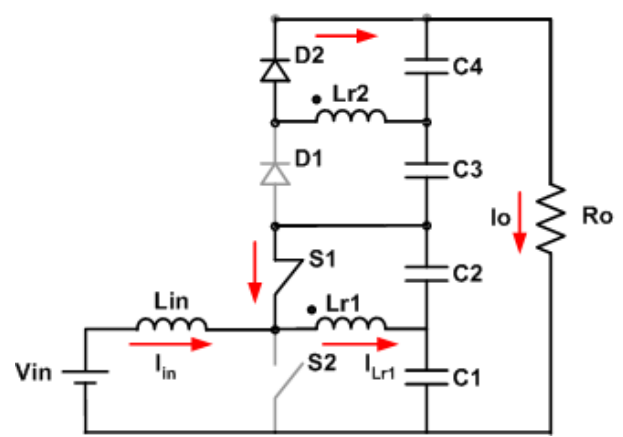

Fig .10. Fourth Stage.

\section{Experimental Results}

This section presents the experimental results from a prototype of the converter presented in Fig 2, considering the specifications given in TABLE I. The waveforms showed certify the obtained simulation results, as can be seen in figure 6 .

The choice of large output capacitors was made based on predicting the use of an inverter connected to the converter output, which would require large capacitors in order to attenuate the low frequency ripple. 
Figure 11 shows the input voltage waveform (Vin = $24 \mathrm{~V})$ and the output voltage $(\mathrm{Vo}=200 \mathrm{~V})$ for the nominal load, proving the correct operation.

Table I. - Converter Specifications.

\begin{tabular}{|c|c|}
\hline Input Voltage & $24 \mathrm{Vdc}$ \\
\hline Output Voltage & $200 \mathrm{Vdc}$ \\
\hline Nominal Power & $500 \mathrm{~W}$ \\
\hline Switching Frequency & $50 \mathrm{kHz}$ \\
\hline Transformer turns ratio (n) & 3 \\
\hline Inductance of $\mathrm{L}_{\mathrm{in}}$ & $120 \mu \mathrm{H}$ \\
\hline Capacitances of $\mathrm{C}_{1}, \mathrm{C}_{2}, \mathrm{C}_{3}$ and $\mathrm{C}_{4}$ & $680 \mu \mathrm{F}$ \\
\hline
\end{tabular}

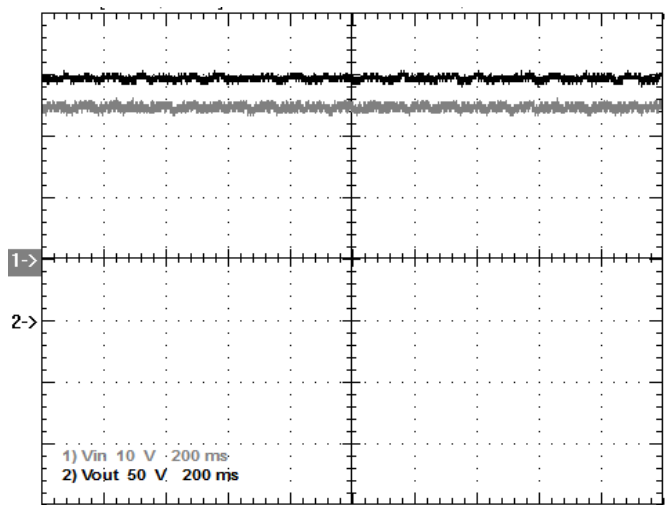

Fig .11. Input and output voltages.

Figure 12 presents the input current waveform (Iin). As can be observed, the average value is $12 \mathrm{~A}$ with a ripple of $10 \%$ for a $300 \mathrm{~W}$ load.

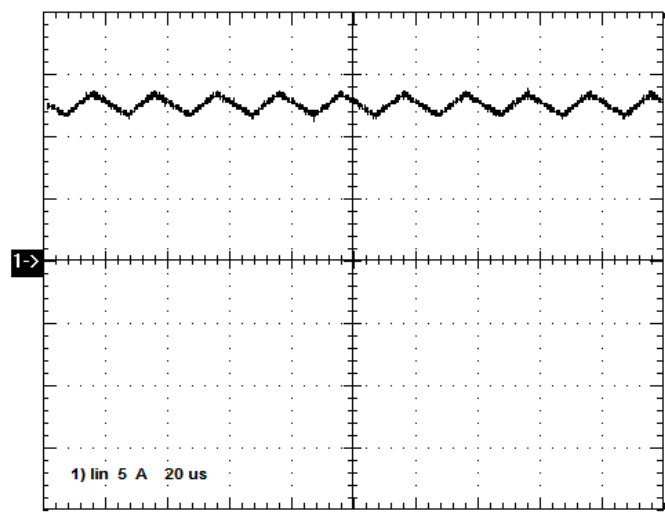

Fig .12. Input current.

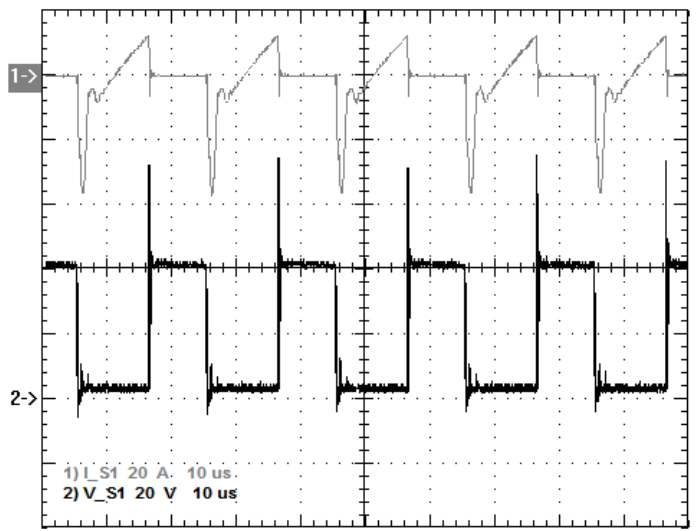

Fig .13. Voltage and current through S1.
Figure 13 presents the voltage and the current during the turn-on period through the switch S1. It must be observed from these figures that switch S1 start to conduct in ZVS mode. Figure 14 presents the voltage and the current during the turn-on period through the switch $\mathrm{S} 2$.

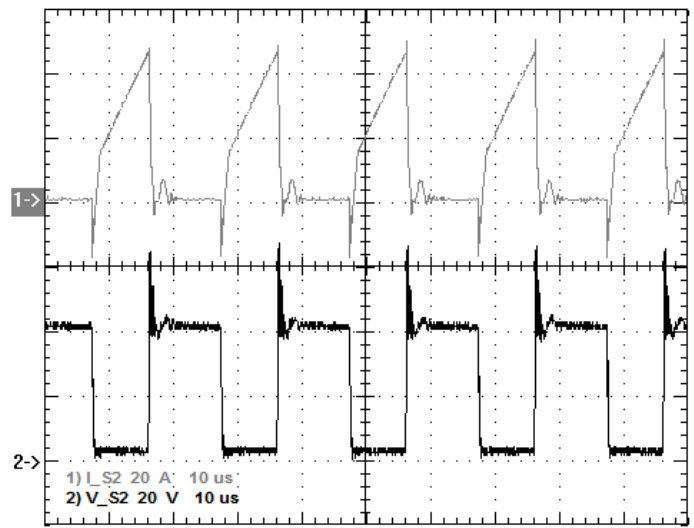

Fig .14. Voltage and current through S2.

Figure 15 presents the voltage across each output capacitor, which are equilibrated. Measured $\mathrm{V}_{\mathrm{C} 1}$ is $25 \mathrm{~V}$, while $\mathrm{V}_{\mathrm{C} 2}$ is $18.1 \mathrm{~V}, \mathrm{~V}_{\mathrm{C} 3}$ is $90 \mathrm{~V}$, and $\mathrm{V}_{\mathrm{C} 4}$ is $74.2 \mathrm{~V}$. With a transformer relation of $1: 3$, it is expected that the voltage across $\mathrm{C} 3$ should be three times the voltage across $\mathrm{C} 1$, and the same relation between $\mathrm{C} 2$ and $\mathrm{C} 4$.

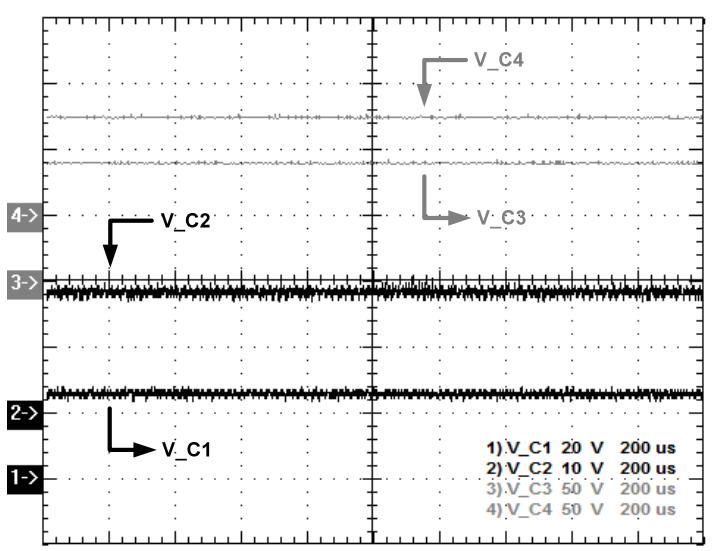

Fig .15. Voltage across $\mathrm{C} 1, \mathrm{C} 2, \mathrm{C} 3$ and $\mathrm{C} 4$.

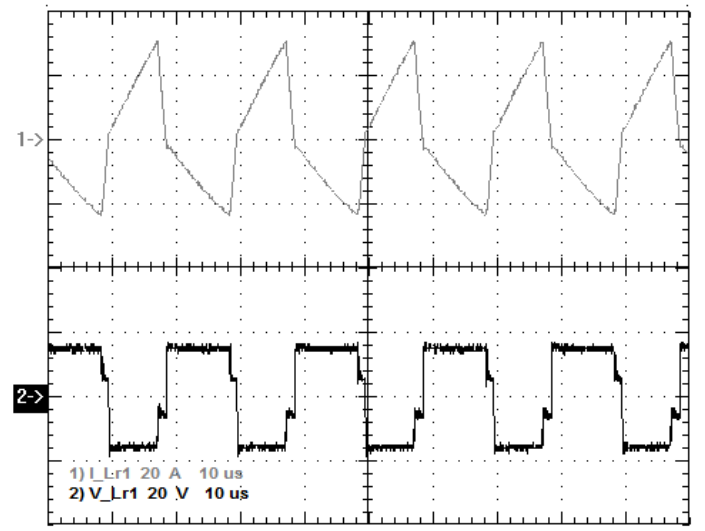

Fig .16. Voltage and current through Lr.

However these relations are not observed on the simulation results, due to the presence of the leakage inductance, which is responsible for the ZVS commutation. 
Figure 16 shows the voltage and current waveforms through the primary side of the transformer for a $300 \mathrm{~W}$ load. The current wa

Figure 17 shows the output voltage esponse considering a solar radiation step up from $0 \%$ to $100 \%$ of the rated condition. One can see an acceptable static and dynamic voltage response, considering the load as the dc link of an inverter. Figure 16 presents the prototype developed in laboratory.

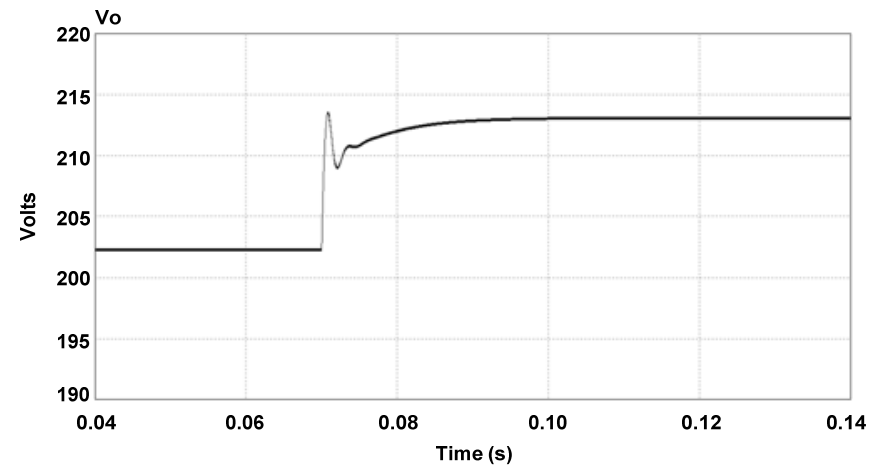

Fig .17. Output voltage response for zero to full load step-up.

Fig. 18 shows the efficiency curve of the developed topology, measured by certified digital equipments. It can be seen a peak efficiency of $96 \%$ for $100 \mathrm{~W}$ and $92.5 \%$ for full load. This efficiency curve can be even improved by the use of schottky diodes in the secondary side, currently not available for this prototype. In Fig. 19 a picture of the developed prototype is shown.

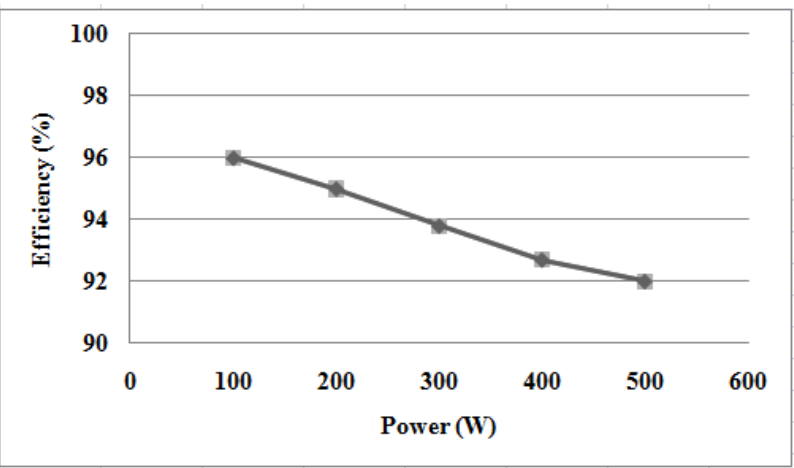

Fig .18. Efficiency.

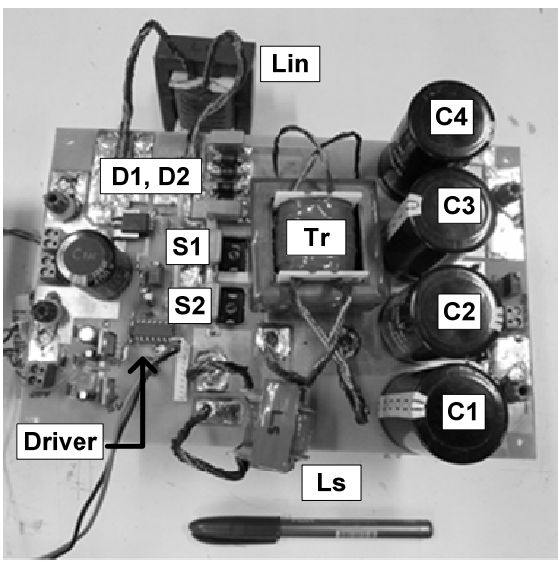

Fig .19. Prototype photography.

\section{Conclusion}

This paper has presented the concept of topologies with integrated capabilities as battery charging from a photovoltaic panel, large step-up voltage gain to feed a dc link of a inverter and soft-switching, in a single stage. During the MPPT operation, the battery charge, discharge and dc link feeding management is inherent to its operation and provides an acceptable voltage regulation. Applying this concept, some topologies derived from the half-bridge boost converter were obtained and described, such as the voltage-multiplier rectifier and also a structure based on the three-state commutation cell. Experimental results obtained from a $500 \mathrm{~W}$ prototype validate the concept, with high efficiency along a wide load range $(>92.5 \%)$, and confirming the satisfactory performance of the structures. Thus, the idea of integrating converters in a single stage seems to be promising on the path to obtain additional topologies feasible to photovoltaic and fuel cell applications.

\section{References}

[1] Silva, R.N.A.L.; Henn, G.A.L.; Praca, P.P.; Barreto, L.H.S.C.; Oliveira, D.S.; Antunes, F.L.M.: 'Soft-switching interleaved boost converter with high voltage gain ', Power Electronics Specialists Conference - PESC 2008, pp. 4157 4161.

[2] Qun Zhao; Fred C. Lee. 'High-Efficiency, High Step-Up DC-DC Converters'. Power Electronics, IEEE Transactions on, 2003. Vol. 18, pp. 65 - 73.

[3] Araujo, S.V.; Torrico-Bascope, R.P.; Torrico-Bascope, G.V.: 'Highly Efficient High Step-Up Converter for Fuel-Cell Power Processing Based on Three-State Commutation Cell', Industrial Electronics, IEEE Transactions on, 2010. Vol. 57, June, pp. 1987-1997.

[4] Bascope, G.V.T.; Barbi,I: 'Generation of a family of nonisolated DC-DC PWM converters using new three-state switching cells '. Power Electronics Specialists Conference. PESC 00 IEEE 31st Annual, 2000. Vol. 2, pp. 858-863.

[5] Prudente, M.; Pfitscher, L.L.; Emmendoerfer, G.; Romaneli, E.F.; Gules, R.: 'Voltage Multiplier Cells Applied to NonIsolated DC-DC Converters'. Power Electronics, IEEE Transactions on, 2008. Vol. 23, pp. 871-887.

[6] Ching-Tsai Pan; Ching-Ming Lai: 'A High-Efficiency High Step-Up Converter With Low Switch Voltage Stress for FuelCell System Applications'. Industrial Electronics, IEEE Transactions on, 2010. Vol. 57, pp. 1998-2006. 